\title{
Development and Evaluation of Paper from Corn Husks (Zea mays L.) and Snake Plant Fibers (Sansevieria zeylanica)
}

\author{
Rainer R. Fiscal, Kristoffer Bryan V. Dandan \\ Laguna State Polytechnic University, Siniloan, Laguna, Philippines \\ Fiscalrainer[at]gmail.com
}

\begin{abstract}
Paper is one of the products that are used for many purposes. In line with this, increasing demand for paper was leading to rapid environment destruction. The present environmental issue can resolve by using non-timber resources for making paper. This study aims to produce quality paper out of corn husks and snake plant fibers. It also seeks to determine the qualities of produced paper through laboratory experiment and sensory evaluation. Experimental design was utilized in developing paper. The results revealed that for the basis weight, pure corn husks obtained the closest standard measurement. For the thickness, pure snake plant fibers, $75 \%$ corn husks and 25\% snake plant fibers, 50\% corn husks and 50\% snake plant fibers, and 25\% corn husks and $75 \%$ snake plant fibers followed the standard measurement. For the burst index, 25\% corn husks and 75\% snake plant fibers obtained the closest standard measurement. On the other hand, for the tensile index, all treatments followed the standard measurement and for the folding endurance, all of the treatments except 50\% corn husk and 50\% snake plant fibers were also followed the standard measurement. Based on the sensory evaluation, the study revealed that $75 \%$ corn husks and $25 \%$ snake plant fibers was the most acceptable among all the treatments. The color of the paper is significantly different with each other as evaluated by the three categories of respondents. The level of acceptability of corn husks and snake plant fibers as raw materials for making paper is significantly different regarding texture, color, and thickness.
\end{abstract}

Keywords: Corn husks, paper, snake plant fibers

\section{Introduction}

The global forests are being depleted for the production of paper products. Every year over 4 billion or $35 \%$ of the world's trees is felled and used in the manufacture of paper products [1]. According to the United Nations Food and Agriculture Organization [2], an estimated 18 million acres (7.3 million hectares) of forest are lost each year because of rapid consumption of timber trees for producing forest products such as paper. In the Philippines, the country lost a third of its forest cover from 1990 to 2005. The Philippine deforestation is down since its peak in the 1980's and 1990's. Widespread logging was responsible for much of the historical forest loss. Although the government bans on timber harvesting, illegal logging still continues today [3].Within this environmental situation, there is an increasing demand for alternative pulp and paper means and become significant challenges for the government agencies to utilize that sources rapid economic development and population growth. Aside from this, the demand for paper is not only in local setting but also in different parts of the world. Therefore, the authors came up with an idea that can resolve this problem.

The non-timber resources like corn husks and snake plant fibers as the raw materials for the paper production can cover a percentage of paper consumptions throughout the world. The researchers utilized these two raw materials to produced non-timber paper. Testing the physical and evaluative properties of the paper out of the combinations of these raw materials was different from other previous studies.

\section{Objectives of the Study}

This study aims to develop and produce paper out of corn husks and snake plant fibers. It seeks to determine the physical qualities of produced paper such as basis weight, thickness, burst index, tensile index and folding endurance through laboratory experiment, testing and results. It also aims to determine the level of acceptability of produced paper based on the sensory evaluation of the respondents regarding texture, durability, color, and thickness.

\section{Materials and Methods}

\subsection{Research Design}

This study development and evaluation of paper from corn husks and snake plant fibers utilized experimental design. The treatment combinations were composed of corn husks and snake plant fibers. The treatment combinations were $\mathrm{T} 1$ pure corn husks; T2 - pure snake plant fibers; T3 - 75\% corn husks and 25\% snake plant fibers; T4 - 50\% corn husks and $50 \%$ snake plant fibers; and T5 - 25\%corn husks and $75 \%$ snake plant fibers.

\subsection{Special Techniques and Procedure}

\section{Collection of Raw Materials}

The corn husks were gathered from the corn vendors along the roads in Lumban, Laguna and the matured snake plant leaves were harvested from the gardens in Siniloan, Laguna. 


\section{International Journal of Science and Research (IJSR) \\ ISSN (Online): 2319-7064}

Index Copernicus Value (2013): 6.14 | Impact Factor (2015): 6.391

The raw materials were thoroughly cleaned using water and separated from other foreign materials. The snake plant fibers and corn husks were cut into 1-inch length and were cooked. About $40 \%$ or $2.50 \mathrm{~kg}$ of caustic soda were mixed with $10 \mathrm{~L}$ of water. The cooking process prepared two sets of mixtures. The first and second mixtures were placed in the stainless casserole with $5 \mathrm{~kg}$ corn husks for the first mixture and $2 \mathrm{~kg}$ of snake plant fibers for the second mixture. The corn husks were boiled for about two hours and five hours for the snake plant fibers. The softened raw materials were placed in screen or cloth and washed with water. The corn husks and snake plant fibers were beaten and blended to separates the fibers thoroughly, and it was formed into a sheet. The pulp was put into $15 \mathrm{~L}$ of water. The fibers were set into the screen by allowing water to drip back into the vat and pressed. Once a stack of damp sheets and felts assembled between boards, pressing of the entire pile follows and it was dried and cut. The paper sheets were cut into its selected size required for laboratory testing and acceptability test.

\section{Laboratory Testing}

The researchers used selected physical properties parameters such as basis weight, thickness, burst index, tensile index and folding endurance to determine the physical properties of the paper. Testing of physical properties of paper contained various parameters. The treatment samples were tested according to Technical Association of the Pulp and Paper Industry- TAPPI $220 \mathrm{sp}-06$ standard procedures under the following room conditions:

a. Dry bulb temperature $\left(23 \pm 1.0{ }^{\circ} \mathrm{C}\right)$ and

b. Relative humidity $(50 \pm 2.0 \%)$.

The basis weight of the paper was the weight per unit area. The thickness determines how bulky or dense paper is. Burst index measures its resistance to rupturing, and it was defined as the hydrostatic pressure needed to burst a paper board sample when it is applied uniformly across its side.The tensile index is indicative of fiber strength, fiber bonding, and fiber length. It can be used as a potential indicator of resistance to web breaking during printing or converting. Folding endurance measures the amount of folding that paper will endure before its tensile strength falls below a standard value of one-kilogram force.

\section{Sensory Evaluation of Paper}

The physical properties of paper such as texture, durability, color, and thickness were determined through sensory evaluation of consumer acceptability of paper. To assess the acceptability of the final product, 30 respondents comprising of 10 students, ten teachers, and ten handicraft makers acted as a panel of the evaluator and were selected using purposive sampling to evaluate the produced paper using a 5-point Likert Scale Quality Scoring. The respondents were asked to rate the paper samples using the score sheet rubrics as they perceive it.

\subsection{Statistical Tools}

Data on the physical qualities of paper developed from corn husks and snake plant fibers such as basis weight, thickness, burst index, tensile index, and folding endurance was analyzed using a standard measurement based on the Technical Association of the Pulp and Paper Industry-TAPPI $220 \mathrm{sp}-06$. For sensory evaluation, the gathered data was treated and analyzed using mean, Friedman test, and KruskalWallis H-test. In testing the level of acceptability of the qualities of produced paper such as texture, durability, color and thickness based on the perception of the respondents mean was utilized. Friedman test was used for testing the difference in the level of acceptability of the treatment combinations for the three categories of respondents. Kruskal-Wallis H-test was used in testing the difference in the level of acceptability of corn husks and snake plant fiber as raw materials in making paper.

\section{Results and Discussion}

Table 1 shows the results of laboratory testing of five samples of paper. Based on the results of the study Treatment 1 or pure corn husks obtained the closest standard measurement regarding basis weight. Treatments 2, 3, 4, and 5 followed the standard measurement with regards to thickness and Treatment 5 or $25 \%$ corn husks and $75 \%$ snake plant fibers obtained the closest standard measurement regarding burst index. On the other hand, concerning tensile index, all the treatments followed the standard measurement while in testing the folding endurance all the treatments followed the given standard measurement except for the Treatment 4 or $50 \%$ corn husks and $50 \%$ snake plant fibers. The results implied that almost all of the treatments followed the standard measurement based on TAPPI $220 \mathrm{sp}-06$.

The laboratory test results of the study were similar to the reports of Yang and Reddy [4], Ververis et al. [5], Fagbemigun et al. [6], Sankar et al. [7], and Kanimozhi [8]. Yang and Reddy reported that the basis weight of the corn husk fibers was $0.5 \mathrm{~mm}$ to about $1 \mathrm{~mm}$ in length and about $100 \mu \mathrm{m}$ in width so that it was used for making light weight products like paper. Ververis et al. reported that softwoods or the non-timber like snake plant with longer fibers have high paper strength. Fagbemigun indicated that the tensile strength of paper sheet produced from the pulp of corn husks could be considered as an alternative raw material for paper making applications. Pulp produced from corn husks can be mixed with softwood, hardwood or recycled paper pulps to produce paper with increased printability, tearing strength and mechanical strength. Sankar reported that snake plant was composed of long fibers, and that is the reason why this combination has higher tensile index compared to raw materials alone. Kanimozhi indicated that the natural cellulose of snake plant fibers has real strength in which it cannot be easily damaged. 


\section{International Journal of Science and Research (IJSR) \\ ISSN (Online): 2319-7064 \\ Index Copernicus Value (2013): 6.14 | Impact Factor (2015): 6.391}

Table 1: Laboratory test results of paper from corn husks and snake plant fibers

\begin{tabular}{|l|l|l|l|l|l|l|}
\hline \multicolumn{1}{|c|}{ Properties } & \multicolumn{1}{c|}{$\begin{array}{c}\text { Standard } \\
\text { Measurement }\end{array}$} & T1 & T2 & T3 & T4 & T5 \\
\hline $\begin{array}{l}\text { Basis Weight, } \\
\mathrm{g} / \mathrm{m}^{2}\end{array}$ & 90 & 91 & 92 & 79 & 97 & 108 \\
\hline Thickness, $\mathrm{mm}$ & $0.1-0.2$ & 0.3 & 0.2 & 0.2 & 0.2 & 0.2 \\
\hline $\begin{array}{l}\text { Burst Index, } \\
\mathrm{kPa}^{*} \mathrm{~m}^{2} / \mathrm{g}\end{array}$ & 2.5 & 1.1 & 1.4 & 1.3 & 1.2 & 2.3 \\
\hline $\begin{array}{l}\text { Tensile Index, } \\
\mathrm{N}^{*} \mathrm{~m} / \mathrm{g}\end{array}$ & $20-40$ & 24 & 29 & 25 & 22 & 31 \\
\hline $\begin{array}{l}\text { Folding } \\
\text { Endurance }\end{array}$ & $7.2-14.5$ & 9.9 & $\begin{array}{l}10 . \\
7\end{array}$ & 7.7 & 5.5 & 10.7 \\
\hline
\end{tabular}

Sensory evaluation of produced paper from corn husks and snake plant fibers as perceived by the respondents is presented in Table 2. Based on the results of the study with regards to texture Treatment 3 or $75 \%$ corn husks and $25 \%$ snake plant fibers obtained the highest mean score of 4.80 interpreted as highly acceptable. The produced paper was smooth and fine. Regarding durability, Treatment 2 or pure snake plant fibers obtained the highest mean score of 4.43 interpreted as highly acceptable. The produced paper was highly resistant, cannot be tear easily and it is very compact. On the other hand, regarding color, Treatment 1 or pure corn husks obtained the highest mean score of 4.77 interpreted as highly acceptable. The produced paper was it has butter yellow or lighter in color that is suitable for making quality paper products. Regarding thickness, all of the treatments are highly acceptable to the respondents and Treatment 3 obtained the highest mean score of 4.63. The produced paper followed the proper standard of $1 \mathrm{~mm}$.

Table 2: Sensory evaluation of paper from corn husks and snake plant fibers

\begin{tabular}{|c|c|c|c|c|}
\hline Treatments & Texture & Durability & Color & Thickness \\
\hline \multirow{2}{*}{ Treatment 1 } & 3.67 & 4.13 & 4.77 & 4.40 \\
& $\mathrm{~A}$ & $\mathrm{~A}$ & $\mathrm{H} \mathrm{A}$ & $\mathrm{HA}$ \\
\hline \multirow{2}{*}{ Treatment 2 } & 4.03 & 4.43 & 2.70 & 4.30 \\
& $\mathrm{~A}$ & $\mathrm{H} \mathrm{A}$ & $\mathrm{F} \mathrm{A}$ & $\mathrm{H} \mathrm{A}$ \\
\hline \multirow{2}{*}{ Treatment 3 } & 4.80 & 4.40 & 4.23 & 4.63 \\
& $\mathrm{H} \mathrm{A}$ & $\mathrm{H} \mathrm{A}$ & $\mathrm{H} \mathrm{A}$ & $\mathrm{H} \mathrm{A}$ \\
\hline \multirow{2}{*}{ Treatment 4 } & 4.30 & 4.40 & 4.10 & 4.60 \\
& $\mathrm{H} \mathrm{A}$ & $\mathrm{H} \mathrm{A}$ & $\mathrm{A}$ & $\mathrm{H} \mathrm{A}$ \\
\hline \multirow{2}{*}{ Treatment 5 } & 4.07 & 4.30 & 3.50 & 4.33 \\
& $\mathrm{~A}$ & $\mathrm{H} \mathrm{A}$ & $\mathrm{A}$ & $\mathrm{H} \mathrm{A}$ \\
\hline
\end{tabular}

* $1.00-1.80$ (U - Unacceptable), $1.81-2.60$ (S U - Slightly Unacceptable), 2.61 - 3.40 (F A - Acceptable), 3.41 - 4.20 (A Acceptable), 4.21 - 5.00 (H A - Highly Acceptable)

Table 3 shows the general acceptability of produced paper from corn husks and snake plant fibers. Based on the sensory evaluation of the respondents the most and highly acceptable among the five treatments was Treatment 3 or $75 \%$ corn husks and $25 \%$ snake plant fibers.

Table 3: General acceptability of paper from corn husks and snake

\begin{tabular}{|l|c|c|}
\multicolumn{2}{c|}{ plant fibers } \\
\hline Treatments & Mean & Verbal Interpretation \\
\hline Treatment 1 & 4.32 & Highly Acceptable \\
\hline Treatment 2 & 4.02 & Acceptable \\
\hline Treatment 3 & 4.70 & Highly Acceptable \\
\hline Treatment 4 & 4.35 & Highly Acceptable \\
\hline Treatment 5 & 4.13 & Acceptable \\
\hline
\end{tabular}

* $1.00-1.80$ (Unacceptable), $1.81-2.60$ (Slightly Unacceptable), $2.61-3.40$ (Acceptable), $3.41-4.20$ (Acceptable), $4.21-5.00$ (Highly Acceptable)

Table 4 shows the difference in the level of acceptability of treatment combinations of paper as perceived by the three categories of respondents. Friedman test failed to detect a significant difference between the treatment combinations and three types of respondents on the texture, durability and thickness of the paper. On the other hand, a significant difference was detected on the color. These imply that the three categories of respondents have the same perception of the texture, durability, and thickness but not in the color of the paper.

Table 4: Difference in the level of acceptability of the treatment combinations and the three categories of respondents

\begin{tabular}{|c|c|c|c|}
\hline Properties & Median & $\begin{array}{c}\text { Computed } \\
\text { Value }\end{array}$ & p-value \\
\hline \multicolumn{4}{|l|}{ Texture } \\
\hline $\mathrm{T} 1$ & 3.90 & 7.13 & $0.129^{\mathrm{NS}}$ \\
\hline $\mathrm{T} 2$ & 4.18 & & \\
\hline $\mathrm{T} 3$ & 4.76 & & \\
\hline $\mathrm{T} 4$ & 3.80 & & \\
\hline $\mathrm{T} 5$ & 4.00 & & \\
\hline \multicolumn{4}{|l|}{ Durability } \\
\hline $\mathrm{T} 1$ & 4.40 & 1.53 & $0.821^{\mathrm{NS}}$ \\
\hline $\mathrm{T} 2$ & 4.40 & & \\
\hline T3 & 4.40 & & \\
\hline $\mathrm{T} 4$ & 4.26 & & \\
\hline T5 & 4.44 & & \\
\hline \multicolumn{4}{|l|}{ Color } \\
\hline $\mathrm{T} 1$ & 3.18 & 10.20 & $0.037^{\mathrm{S}}$ \\
\hline $\mathrm{T} 2$ & 3.90 & & \\
\hline $\mathrm{T} 3$ & 4.06 & & \\
\hline $\mathrm{T} 4$ & 4.48 & & \\
\hline $\mathrm{T} 5$ & 2.48 & & \\
\hline \multicolumn{4}{|l|}{ Thickness } \\
\hline $\mathrm{T} 1$ & 4.40 & 9.27 & $0.055^{\mathrm{NS}}$ \\
\hline $\mathrm{T} 2$ & 4.70 & & \\
\hline T3 & 4.70 & & \\
\hline $\mathrm{T} 4$ & 4.52 & & \\
\hline T5 & 4.38 & & \\
\hline
\end{tabular}

$\mathrm{df}=4$

$\mathrm{S}-$ Significant

NS - Not Significant

Table 5 shows the difference in the level of acceptability of corn husks and snake plant fibers as raw materials for paper regarding qualities. Kruskal-Wallis H-Test failed to detect a significant difference in the degree of acceptability of corn husks and snake plant fibers as raw materials for paper regarding durability. On the other hand, significant differences were detected on the texture, color, and thickness. This difference indicates that the texture, color, and thickness of the produced paper were highly acceptable by the respondents but not in the durability of the paper. 


\section{International Journal of Science and Research (IJSR) \\ ISSN (Online): 2319-7064 \\ Index Copernicus Value (2013): 6.14 | Impact Factor (2015): 6.391}

Table 5: Difference in the level of acceptability of corn husks and snake plant fibers as raw materials for paper regarding qualities

\begin{tabular}{|c|c|c|c|}
\hline Properties & Median & $\begin{array}{c}\text { Computed } \\
\text { Value }\end{array}$ & $p$-value \\
\hline \multicolumn{4}{|l|}{ Texture } \\
\hline $\mathrm{T} 1$ & 4.00 & 26.304 & $0.001^{\mathrm{S}}$ \\
\hline $\mathrm{T} 2$ & 4.0 & & \\
\hline $\mathrm{T} 3$ & 5.00 & & \\
\hline $\mathrm{T} 4$ & 4.00 & & \\
\hline $\mathrm{T} 5$ & 4.00 & & \\
\hline \multicolumn{4}{|l|}{ Durability } \\
\hline $\mathrm{T} 1$ & 4.00 & 2.960 & $0.565^{\mathrm{NS}}$ \\
\hline $\mathrm{T} 2$ & 5.00 & & \\
\hline $\mathrm{T} 3$ & 5.00 & & \\
\hline $\mathrm{T} 4$ & 4.00 & & \\
\hline T5 & 4.00 & & \\
\hline \multicolumn{4}{|l|}{ Color } \\
\hline $\mathrm{T} 1$ & 5.00 & 58.028 & $0.009^{\mathrm{S}}$ \\
\hline $\mathrm{T} 2$ & 2.00 & & \\
\hline $\mathrm{T} 3$ & 5.00 & & \\
\hline T4 & 4.00 & & \\
\hline $\mathrm{T} 5$ & 3.00 & & \\
\hline \multicolumn{4}{|l|}{ Thickness } \\
\hline $\mathrm{T} 1$ & 4.50 & 9.517 & $0.049^{\mathrm{S}}$ \\
\hline $\mathrm{T} 2$ & 4.00 & & \\
\hline $\mathrm{T} 3$ & 5.00 & & \\
\hline $\mathrm{T} 4$ & 5.00 & & \\
\hline $\mathrm{T} 5$ & 4.00 & & \\
\hline
\end{tabular}

$\mathrm{df}=4$

crit. value $=9.487729$

probability $=0.05$

$\mathrm{S}$ - Significant

NS - Not Significant

\section{Conclusion and Recommendation}

From the result of the study, it concluded that corn husks, snake plant fibers, and its combinations followed the standard measurement set by the TAPPI $220 \mathrm{sp}-06$. Most of the treatment combinations of the produced paper were acceptable as raw materials in making paper. Among all the treatment combinations, Treatment 3 or $75 \%$ corn husks and $25 \%$ snake plant fibers was the most acceptable. The color of the produced paper was evaluated differently by the three categories of respondents. The texture, color, and thickness of the produced paper from corn husks and snake plant fibers have been assessed differently by the respondents. Hence, the following recommendations are forwarded: Treatment 1 can be used to produce lightweight products because it obtained closest basis weight standard measurement; Treatment 5 can be used in making durable products like paper bag because of its ideal thickness and high burst index; All the Treatment combinations can be used to produce handicraft products because of its ideal tensile index; Treatments $1,2,3$ and 5 can be used in making quality paper products because of its ideal folding endurance; and further studies were advisable to develop other raw materials to produced eco-friendly paper and other stuff.

\section{References}

[1] Martin, S. (2011). Paper Chase, http:/www.ecology.com/2011/09/10/paper/chase/

[2] FAOSTAT (2010). FAO Statistical Database. http://faostat.fao.org

[3] FAO Forestry Paper. (2010). Global Forest Resources Assessment 2010 . http://www.fao.org/docrep/013/i1757e/i1757e.pdf

[4] Yang, Y. and Reddy, N. (2007). Natural cellulosic fiber bundles from cornhusk and a method for making the same,

http://www.google.com/patents/WO2007008228A1?cl= en

[5] Ververis, C., Georghiou, K., Christodoulakis, N., Santas, P., \& Santas, R. (2004). Fiber dimensions, lignin and cellulose content of various plant materials and their suitability for paper production, Industrial and Crops Products, 19, 245-254

[6] Fagbemi, O. D., Otitoju, O., Mgbachiuzor, E. \& Igwe, C. C. (2014). Pulp andpaper making potential of corn husk, International Journal of Agri. Science, 4 (4), 209213

[7] Sankar, P. H., Mohana Reddy, Y. V., Hemachandra Reddy, K., Ashok Kumar, M., Ramesh, A. (2014). The effect of fiber length on tensile properties of polyester resin composites reinforced by the fibers of Sansevieria trifasciata, International Letters of Natural Sciences, 8, $7-13$

[8] Kanimozhi, M. (2011). Investigating the physical characteristics of Sansevieriatrifasciatafibre, International Journal of Scientific and Research Publications, 1 (1), 1-4

\section{Author Profile}

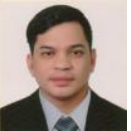

Rainer R. Fiscal received the B.S. degree in Education major in General Science from University of Rizal System in 2003 and M.A. in Teaching Science and Technology from Laguna State Polytechnic University in 2014. He is now with LSPU as College Instructor.

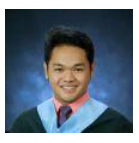

Kristoffer Bryan V. Dandan received the B.S. degree in Education major in Biological Science from Laguna State Polytechnic University in 2016. He is now with PSBC as Basic Education Teacher. 